Original Article

\title{
EFFECT OF MYOPIA ON PRIMARY OPEN ANGLE GLAUCOMA
}

\author{
MENAKURU SREYA REDDY, DIVYA N. ${ }^{*}$, PANIMALAR A. VEERAMANI, BINDU BHASKARAN ${ }^{4}$ \\ ${ }^{1}$ Department of Ophthalmology, Saveetha Medical College, Chennai, Tamil Nadu, India \\ Email: divya.q7@gamil.com
}

Received: 15 Jul 2020, Revised and Accepted: 12 Sep 2020

\section{ABSTRACT}

Objective: It is a retrospective study to evaluate the effect of myopia on primary open-angle glaucoma by classifying the eyes into NMG (nonmyopic glaucoma), HMG (highly myopic glaucoma) And MMG (mild to moderate myopic glaucoma).

Methods: The study was performed on 120 patients with primary open-angle glaucoma who were medically treated. Any participant who had surgery done was excluded from the study. The relation between glaucoma and different myopia and progression were assessed on the basis of age, gender, risk factors.

Results: Out of the 120 cases assessed, 46 [38 percent] were female and 74 [ 62 percent] were males. On the basis of age there were 9 cases between 31-40 y, 30 cases between the ages 41-50, 40 cases between 51-60, 32 cases between 61-70 and 9 cases between 71-80, on the basis of myopia 59 [49 percent] were NMG 47 [39 percent] were MMG and 14 [12 percent] were HMG. On the basis of risk factors,12 of them had Diabetes Mellitus, 7 had Hypertension, 7 had a history of steroid use, 3 had a history of migraines and 6 of them had a family history of glaucoma. In the observed one year period 73 percent if the cases were not progressive while 27 percent were progressive. In this study, it has been observed that the males are more commonly affected and the age group with the most cases was the 51 to 60 age group. The majority of the cases showed no risk factors though Diabetes Mellitus is the most common. The progression of the disease is seen more frequently in cases associated with Diabetes Mellitus and Hypertension. In MMG 12 out of the 47 cases were progressive and in NMG 15 out of the 59 cases were progressive.

Conclusion: Though high myopia is important in the pathogenesis of glaucoma there was no evidence that high myopia increases the progression of the disease of the 14 cases, only 5 were progressive.

Keywords: Myopia, Primary open-angle glaucoma, NMG, HMG, MMG, Diabetes Mellitus, Hypertension

(C) 2020 The Authors. Published by Innovare Academic Sciences Pvt Ltd. This is an open access article under the CC BY license (http://creativecommons.org/licenses/by/4.0/) DOI: http://dx.doi.org/10.22159/ijcpr.2020v12i6.40303. Journal homepage: https://innovareacademics.in/journals/index.php/ijcpr

\section{INTRODUCTION}

Myopia is a refractive error of the eye that makes it difficult to see objects that are far away without optical correction. Although myopia can be caused by lens or corneal curvature or by other factors, axially elongated eyes is the cause for a majority of all myopic cases. Axial elongation can affect the eye's intraocular structure (optic disc or macula), where glaucomatous damage can occur.

An association between myopia and primary open-angle glaucoma has been recognized for decades and has been studied in numerous case studies. Glaucoma, one of the leading causes of irreversible blindness in the adult population worldwide, as a progressive optic neuropathy [1]. Primary open-angle glaucoma (POAG) is the most commonly reported type of glaucoma in population studies conducted worldwide. Elevated intraocular pressure is a wellknown major risk factor for POAG. Myopia has also been found to have an influence on intraocular pressure (IOP). Reduced IOP slows the development or slows the progression of glaucoma.

In a case-control study, myopic refractive error was found to be significantly correlated with ocular hypertension $(\mathrm{OH})$ [2]. An Israeli study of 2403 subjects found a significant relationship between myopia and increasing IOP, particularly in persons of North African or Asian descent [3]. Other studies have documented higher applanation (abnormal flattening of the cornea) pressures in myopic patients [4], which included children [5], or in participants with increased axial length [6], but a UK study found no significant relationship with IOP [7] or in myopic anisometropia [8]. There was also found to be an affiliation with myopia and low-tension glaucoma [9]. However, a study on young Chinese myopic eyes with a glaucomatous optic disc tracked for about $7 \mathrm{y}$ did not record any progression in their optic discs, irrespective of the glaucoma treatment [10]. Furthermore, two Japanese studies have stated that myopia is a preventive factor for the progression of glaucoma $[11,12]$.
High myopia is considered to have a fairly different pathology than mild to moderate myopia on the basis of the progression of glaucoma. Highly myopic eyes are associated with a more aggressive pathological changes in the posterior pole of the eye (which includes the optic disc and macula) which leads to further deterioration, whereas myopic changes in mild to moderate myopia usually tend to remain the same after adolescence $[13,14]$. Some studies have compared highly myopic glaucomatous eyes compared to non highly myopic glaucomatous eyes and have noted that different retinal nerve fiber layer (RNFL) involvement patterns are seen, suggesting that the pattern of progression may differ in myopic cases of varying severity [15]. Hence based on the degree of refractive error myopia was divided into 3 sub-groups: non-myopic, mildly to moderately myopic, and highly myopic.

Myopia is a common condition and its incidence in young people is increasing; hence, to explore the effect of myopia on glaucoma longitudinal cohort data of medically treated primary open-angle glaucoma patients was analyzed.

\section{METHODS AND MATERIALS}

A retrospective review of the medical records of all subjects who were evaluated by the Ophthalmology Department of Saveetha Medical College and Hospital from March 2019 to February 2020. At the initial test, each participant received a comprehensive ophthalmological examination, including a review of the medical history, measurement of visual acuity, provovative test, slit-lamp biomicroscopy, Goldmann applanation tonometry, gonioscopy, central corneal thickness (CCT) measurement and Postmydriatic test.

The inclusion criteria was a subject with a visual acuity of $20 / 40$ or better, the presence of a normal anterior chamber, an open angle on slit-lamp and gonioscopic examinations, glaucomatous optic nerve damage (the presence of focal thinning of the neuroretinal rim or 
notching) and glaucomatous Visual Field defects. All of the subjects with glaucoma in our study were monitored at 3-month intervals. All tests were conducted during the same visit or within a 2-week span. All participants received medical therapy during the follow-up period. If the subject underwent intraocular surgery or laser therapy during the follow-up period, only data collected before these surgeries were included and analyzed.

In terms of risk factors, the presence of Diabetes was confirmed from history or a fasting blood glucose of $140 \mathrm{mg} \%$ or higher [16]. Patients were considered Hypertensive when systolic blood pressure was $\geq 160 \mathrm{mmHg}$ or diastolic blood pressure was $\geq 95$ $\mathrm{mmHg}$ and were under anti-hypertensive therapy. A family history of glaucoma, a typical history of migraine, [17] and a history of steroid use [18] are also considered risk factors. On the basis the level of spherical equivalent the eyes of the participants were divided into the following three: a non-myopic group ( $>0 \mathrm{D}, \mathrm{NMG}$ ), a mild to moderate myopic group ( 0 t6 $\mathrm{D}, \mathrm{MMG})$, and a highly myopic group $f(\mathrm{D}, \mathrm{HMG})$. Glaucomatous progression was determined based on two criteria, optic disc and VF progression.

\section{RESULTS AND DISCUSSION}

Out of the 120 cases assessed 46 [38 percent] were female and 74 [62 percent] were males [table 1 and fig. 1]. Out of the 46 females 22 were non myopic 17 were mild or moderate myopic and 7 had high myopia and out of the 74 males 37 were non-myopic 30 were mild or moderate myopic and 7 had high myopia [table 4 and fig. 4 ]. On the basis of age there were 9 cases between $31-40 \mathrm{y}, 30$ cases between the ages 41-50, 40 cases between 51-60, 32 cases between 61-70 and 9 cases between 71-80 [table 2 and fig. 2].

Table 1: Gender distribution of myopia

\begin{tabular}{ll}
\hline Gender & Count \\
\hline Female & $38 \%$ \\
Male & $62 \%$ \\
Grand total & $100.00 \%$ \\
\hline
\end{tabular}

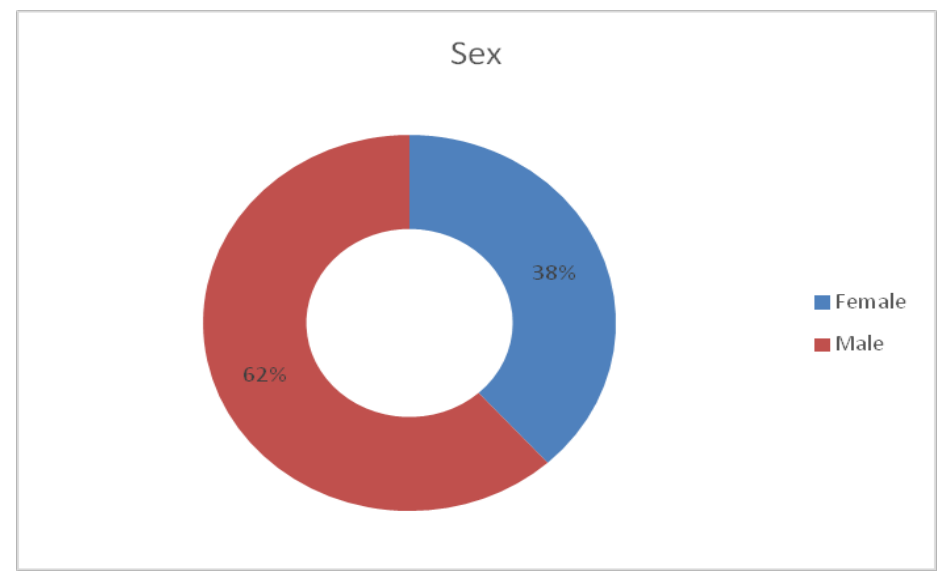

Fig. 1: Gender distribution of myopia

Out of the 120 glaucoma cases 59 [49 percent] were NMG 47 [39 percent] were MMG and 14 [12 percent] were HMG [table 3 and fig. 3 ]. The risk factors taken into consideration in thus study are Diabetes Mellitus, Hypertension, Steroid use, Migraine, Family history. Of the total 12 of them had Diabetes Mellitus, 7 had Hypertension, 7 had a history of steroid use, 3 had a history of migraine and 6 of them had a family history of glaucoma [table 5 and fig. 5] [table 6 and fig. 6].

Table 2: Classification of myopia on the basis of age

\begin{tabular}{ll}
\hline Age & Classification as per age \\
\hline $31-40$ & 9 \\
HMG & 5 \\
MMG & 3 \\
NMG & 1 \\
$41-50$ & 30 \\
HMG & 9 \\
MMG & 8 \\
NMG & 13 \\
M1-60 & 40 \\
NMG & 24 \\
$61-70$ & 16 \\
MMG & 32 \\
NMG & 9 \\
$71-80$ & 23 \\
MMG & 9 \\
NMG & 3 \\
Grand total & 6 \\
\hline
\end{tabular}




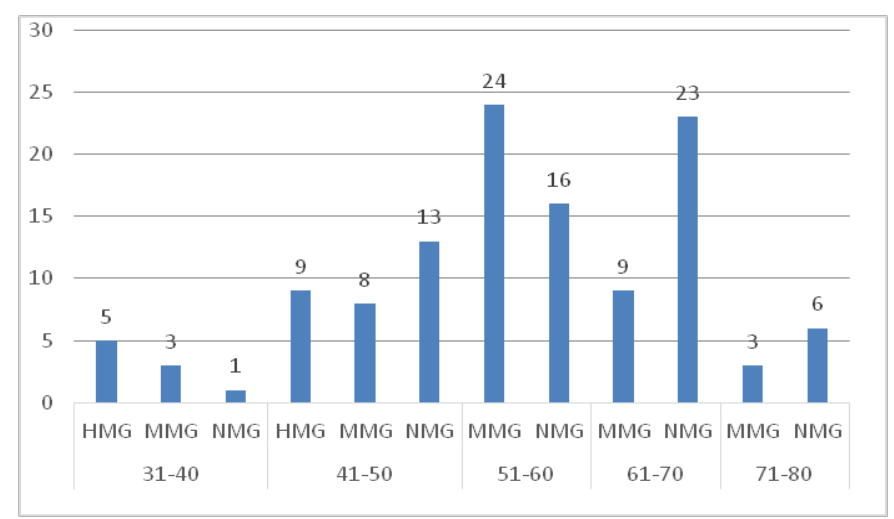

Fig. 2: Classification of myopia on the basis of age

Table 3: Classification of glaucoma on the basis of NMG, HMG and MMG

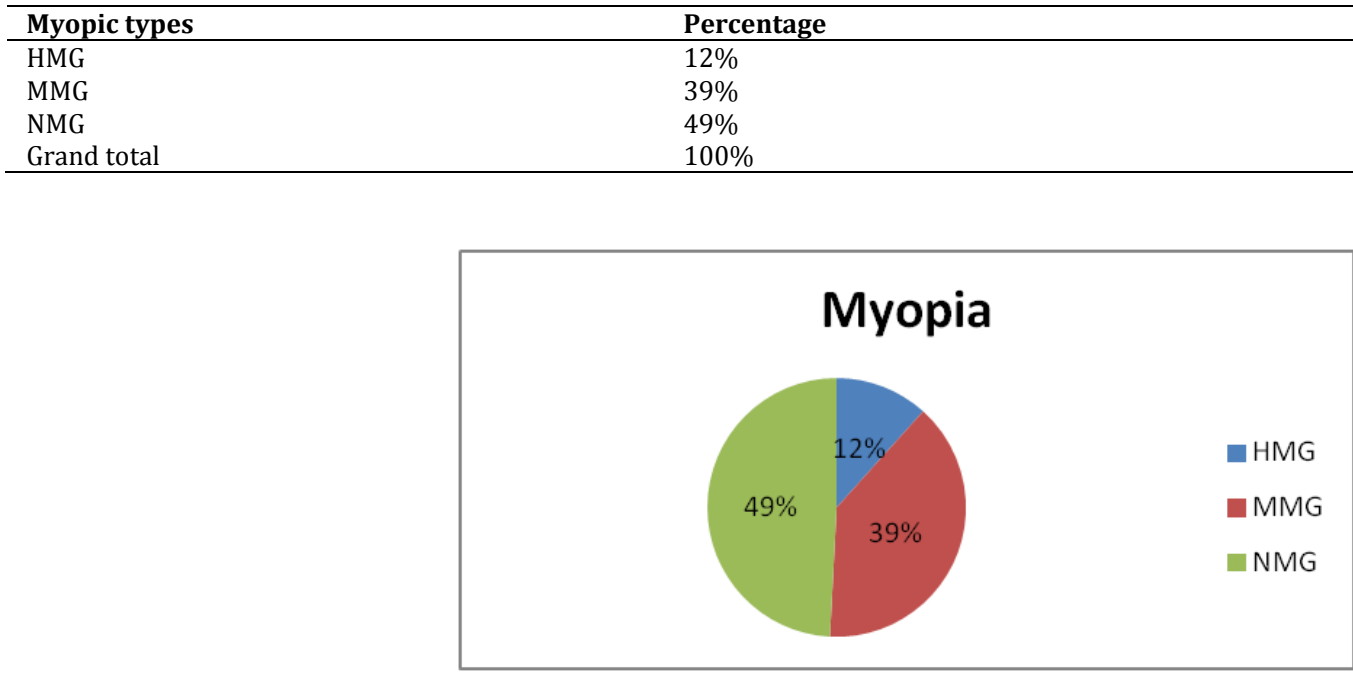

Fig. 3: Classification of glaucoma on the basis of NMG, HMG and MMG

Table 4: Classification on the basis of sex and myopia

\begin{tabular}{ll}
\hline Gender and myopic type & Number \\
\hline Female & 46 \\
HMG & 7 \\
MMG & 17 \\
NMG & 22 \\
Male & 74 \\
HMG & 7 \\
MMG & 30 \\
NMG & 37 \\
\hline
\end{tabular}

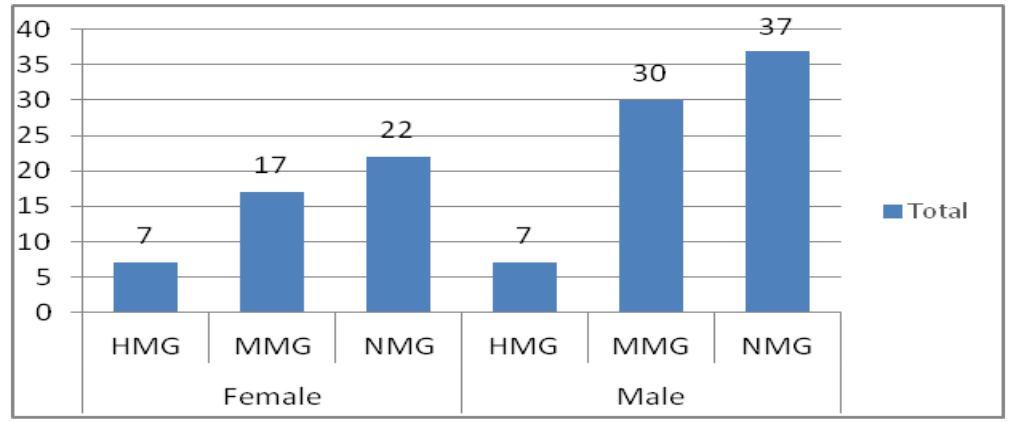

Fig. 4: Classification on the basis of sex and myopia 
Table 5: Risk factors observed

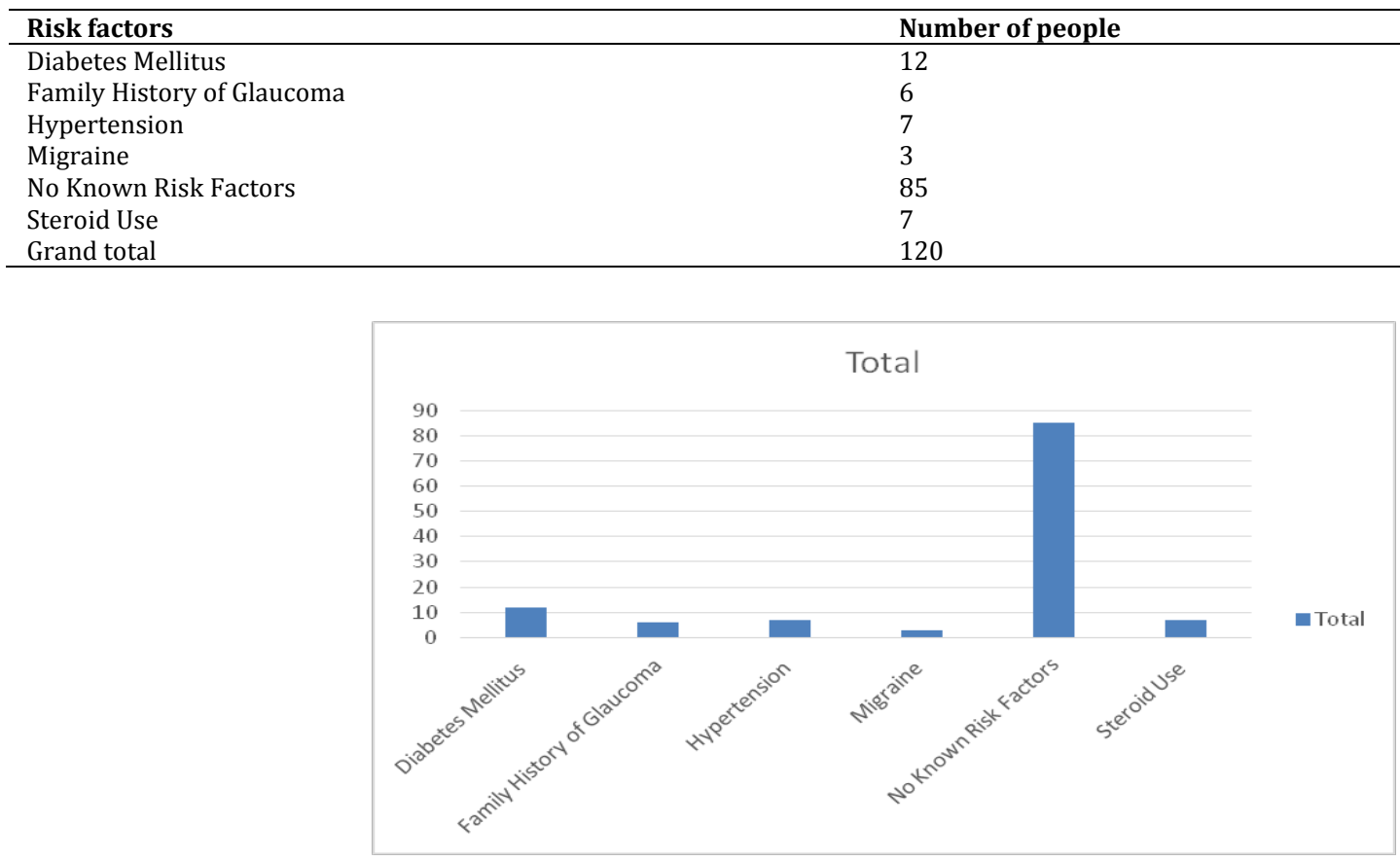

Fig. 5: Risk factors observed

Table 6: Classification on the basis of myopia and risk factors

\begin{tabular}{|c|c|}
\hline Myopic type with associated risk factor & Number of people \\
\hline HMG & 14 \\
\hline Diabetes Mellitus & 3 \\
\hline Migraine & 1 \\
\hline No Known Risk Factors & 9 \\
\hline Steroid Use & 1 \\
\hline MMG & 47 \\
\hline Diabetes Mellitus & 4 \\
\hline Family History of Glaucoma & 3 \\
\hline Hypertension & 4 \\
\hline No Known Risk Factors & 34 \\
\hline Steroid Use & 2 \\
\hline NMG & 59 \\
\hline Diabetes Mellitus & 5 \\
\hline Family History of Glaucoma & 3 \\
\hline Hypertension & 3 \\
\hline Migraine & 2 \\
\hline No Known Risk Factors & 42 \\
\hline Steroid Use & 4 \\
\hline Grand total & 120 \\
\hline
\end{tabular}

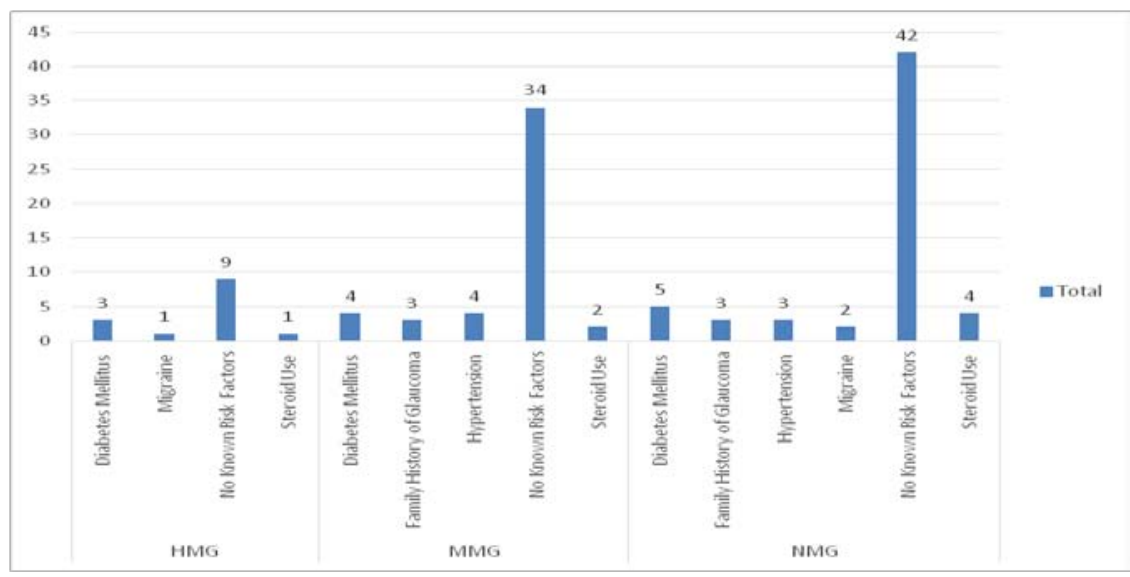

Fig. 6: Classification on the basis of myopia and risk factors 
In the observed one-year period 73 percent if the cases were not progressive while 27 percent were progressive. Out of the 14 HMG cases 9 were non-progressive and 5 were progressive, in MMG 12 out of 47 were progressive and in NMG 15 out of the 59 were progressive.

Table 7: On the basis of progression

\begin{tabular}{ll}
\hline Progression & Percentage of people \\
\hline Non-Progressive & $73 \%$ \\
Progressive & $27 \%$ \\
Grand total & $100.00 \%$ \\
\hline
\end{tabular}

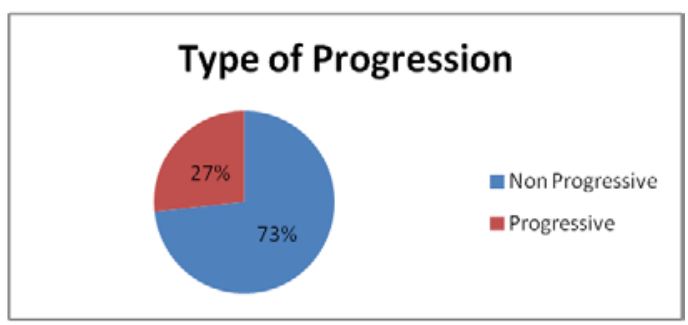

Fig. 7: On the basis of progression

Table 8: Progression of glaucoma depending on myopia

\begin{tabular}{ll}
\hline Myopic type with associated progression & Number of people \\
\hline HMG & 14 \\
Non Progressive & 9 \\
Progressive & 5 \\
MMG & 47 \\
Non Progressive & 35 \\
Progressive & 12 \\
NMG & 59 \\
Non Progressive & 44 \\
Progressive & 15 \\
Grand total & 120 \\
\hline
\end{tabular}

Table 9: Association of glaucoma with risk factors and progression

\begin{tabular}{|c|c|}
\hline Glaucoma types & Count of MYOPIA \\
\hline HMG & 14 \\
\hline Non-Progressive & 9 \\
\hline Diabetes Mellitus & 1 \\
\hline Migraine & 1 \\
\hline No Known Risk Factors & 6 \\
\hline Steroid Use & 1 \\
\hline Progressive & 5 \\
\hline Diabetes Mellitus & 2 \\
\hline No Known Risk Factors & 3 \\
\hline MMG & 47 \\
\hline Non-Progressive & 35 \\
\hline Family History of Glaucoma & 2 \\
\hline No Known Risk Factors & 32 \\
\hline Steroid Use & 1 \\
\hline Progressive & 12 \\
\hline Diabetes Mellitus & 4 \\
\hline Family History of Glaucoma & 1 \\
\hline Hypertension & 4 \\
\hline No Known Risk Factors & 2 \\
\hline Steroid Use & 1 \\
\hline NMG & 59 \\
\hline Non-Progressive & 44 \\
\hline Family History of Glaucoma & 2 \\
\hline Hypertension & 1 \\
\hline Migraine & 1 \\
\hline No Known Risk Factors & 38 \\
\hline Steroid Use & 2 \\
\hline Progressive & 15 \\
\hline Diabetes Mellitus & 5 \\
\hline Family History of Glaucoma & 1 \\
\hline Hypertension & 2 \\
\hline Migraine & 1 \\
\hline No Known Risk Factors & 4 \\
\hline Steroid Use & 2 \\
\hline Grand total & 120 \\
\hline
\end{tabular}




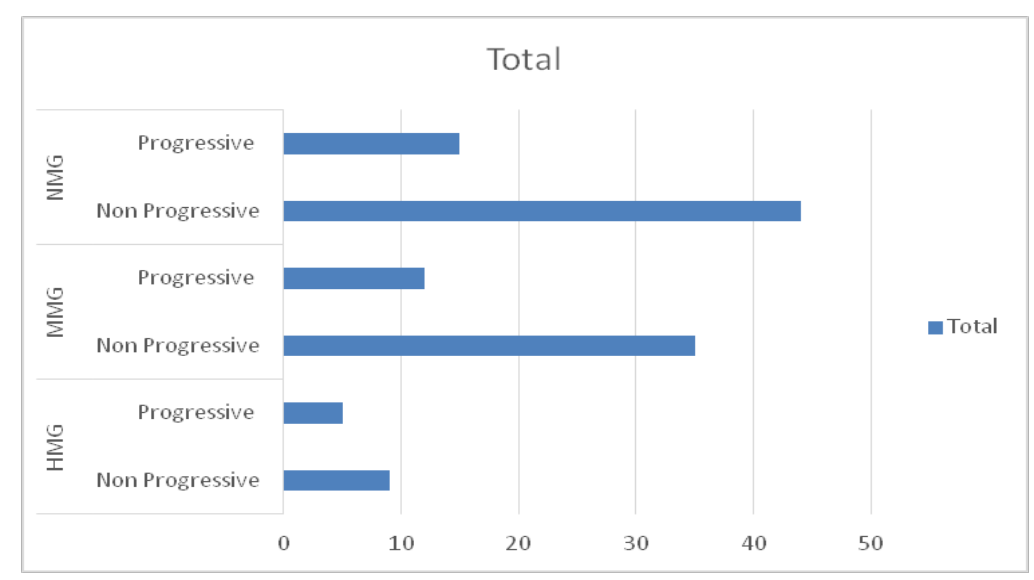

Fig. 8: Progression of glaucoma depending on myopia

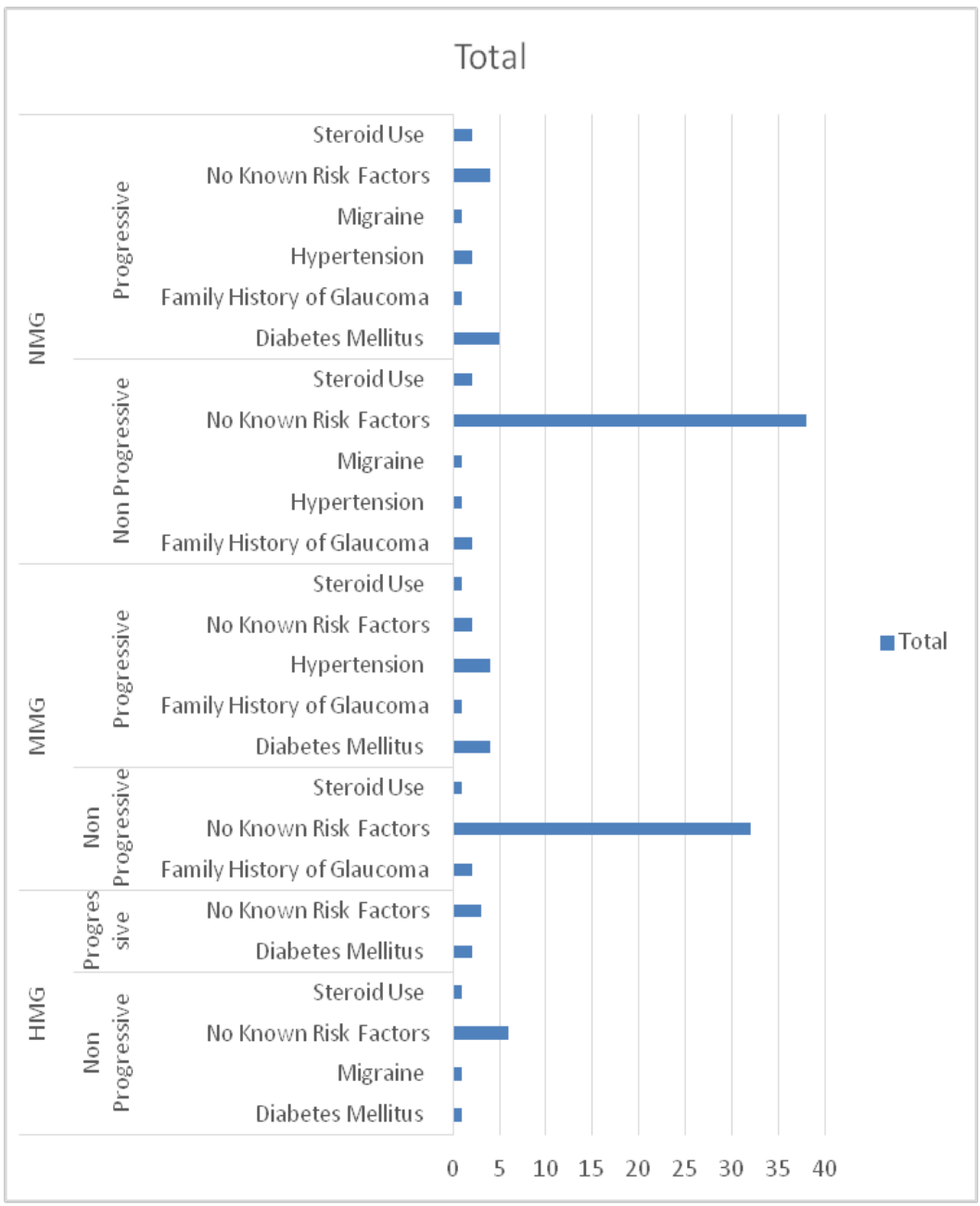

Fig. 9: Association of glaucoma with risk factors and progression

Myopia as a risk factor for glaucoma is backed by population studies, but what remains controversial is the link between myopia and increased susceptibility to or progression of glaucoma [19]. Population-attributable risk assessment is very important to focus the medical and public health interventions based on the risk factors causing the most damage in the community [20].

In this study, it has been observed that the males are more commonly affected and the most common age group was between 51 to 60 . Though Diabetes is the commonest risk factor the majority of the cases have no known risk factors. Also the progression of the disease is seen more frequently in cases associated with Diabetes Mellitus and Hypertension. In MMG 12 out of the 47 cases were progressive and in NMG 15 out of the 59 cases were progressive. Though high myopia is important in the pathogenesis of glaucoma there was no evidence that high myopia increases the progression of the disease [Out of the 14 cases, only 5 were progressive]. Because glaucomatous damage is assessed based on structural changes in the optic disc or functional changes in the VF, and as these structural and functional changes may not occur. Out of the 14 HMG cases 9 
showed no progression, while only 5 were progressive. This correlation may be explained by the increased difficulty in detecting progression by optic disc photographs in highly myopic glaucomatous eyes. Highly myopic eyes may show a tilted optic disc with large peripapilllary atrophy, which makes the evaluation of glaucomatous neuroretinal rim changes difficult [21].

Our current study has several limitations, our participants were included and categorized on the basis of refractive error. Axial length measurement is a more direct assessment of the degree of myopia, as myopia can also be caused by lens changes or other factors. However, axial length is strongly associated with refractive error, and eyes with visually significant lens changes were not included in our analysis. Since this study was a retrospective one, there is a possibility that the participants were treated with the medication of varying aggressiveness as required by their target pressures. Thus, this should be considered in the interpretation of our results. However, most of our study participants had wellcontrolled IOP during the follow-up period (the relatively shorter follow-up period should be acknowledged as another limitation).

\section{CONCLUSION}

In conclusion, myopia is a major risk factor for primary open-angle glaucoma, other systemic diseases, age and gender also can be considered as risk factor with raised IOP is seen as a modifiable risk factor. Also no level of myopia was associated with glaucoma progression; high myopia in our study had a preventive effect on glaucoma progression. This is due to lower progression detection rate due to the use of structural criteria that occurs because of difficulty in detecting the optic disc changes in highly myopic eyes.

\section{FUNDING}

Nil

\section{AUTHORS CONTRIBUTIONS}

All the authors have contributed equally.

\section{CONFLICT OF INTERESTS}

Declared none

\section{REFERENCES}

1. Loyo Berrios NI, Blustein JN. Primary open glaucoma and myopia: a narrative review. WMJ 2007;106:85-9, 95.

2. Seddon JM, Schwartz B, Flowerdew G. Case-control study of ocular hypertension. Arch Ophthalmol 1983;101:891-4.

3. David R, Zangwill LM, Tessler Z, Yassur Y. The correlation between intraocular pressure and refractive status. Arch Ophthalmol 1985;103:1812-5.
4. Abdalla MI, Hamdi M. Applanation ocular tension in myopia and emmetropia. Br J Ophthalmol 1970;54:122-5.

5. Quinn GE, Berlin JA, Young TL. Association of intraocular pressure and myopia in children. Ophthalmology 1995;102:180-5.

6. Tomlinson A, Phillips CI. Applanation tension and axial length of the eyeball. Br J Ophthalmol 1970;54:548-53.

7. Lotufo D, Ritch R, Szmyd L Jr, Burris JE. Juvenile glaucoma, race, and refraction. JAMA 1989;261:249-52.

8. Bonomi L, Mecca E, Massa F. Intraocular pressure in myopic anisometropia. Int Ophthalmol 1982;5:145-8.

9. Leighton DA, Tomlinson A. Ocular tension and axial length of the eyeball in open-angle glaucoma and low tension glaucoma. Br J Ophthalmol 1973;57:499-502.

10. Doshi A, Kreidl KO, Lombardi L. Nonprogressive glaucomatous cupping and visual \#eld abnormalities in young Chinese males. Ophthalmology 2007;114:472-9.

11. Sakata R, Aihara M, Murata H. Contributing factors for progression of visual \#eld loss in normal-tension glaucoma patients with medical treatment. J Glaucoma 2013;22:250-4.

12. Araie M, Shirato S, Yamazaki Y. Risk factors for progression of normal-tension glaucoma under $\beta$-blocker monotherapy. Acta Ophthalmol 2012;90:337-43.

13. Bell GR. Biomechanical considerations of high myopia: part I-physiological characteristics. J Am Optom Assoc 1993;64:3328.

14. Saw SM, Gazzard G, Shih Yen EC. Myopia and associated pathological complications. Ophthalmic Physiol Opt 2005;25:381-91.

15. Kimura Y, Hangai M, Morooka S, Retinal nerve \#ber layer defects in highly myopic eyes with early glaucoma. Invest Ophthalmol Vis Sci 2012;53:6472-8.

16. Mitchell P, Smith W, Chey T, Healey PR. Open-angle glaucoma and diabetes: the blue mountains eye study, Australia. Ophthalmology 1997;104:712-8.

17. Wang JJ, Mitchell $P$, Smith W. Is there an association between migraine headache and open-angle glaucoma? Findings from the blue mountains eye study. Ophthalmology 1997;104:1714-9.

18. Cumming RG, Mitchell $\mathrm{P}$, Leeder SR. Use of inhaled corticosteroids and the risk of cataracts. $\mathrm{N}$ Engl J Med 1997;337:8-14.

19. Chang RT. Myopia and glaucoma. Int Ophthalmol Clin 2011;51:53-63.

20. Perera SA, Wong TY, Tay WT, Foster PJ, Saw SM, Aung T. Refractive error, axial dimensions, and primary open-angle glaucoma: the singapore malay eye study. Arch Ophthalmol 2010;128:900-5.

21. Kim TW, Kim M, Weinreb RN. Optic disc change with incipient myopia of childhood. Ophthalmology 2012;119:21-6. 